\title{
Plano de Cultura Infância do Ceará:um exercício de planejamento e resultado de escuta de demandas sociais ${ }^{1}$
}

\author{
Plan de Cultura Infantil de Ceará: un ejercicio de planificación \\ y resultado de las demandas sociales
}

\author{
Ceará Childhood Culture Plan: \\ a planning exercise and a result of social demands
}

\author{
Deborah Rebello Lima ${ }^{2}$ \\ Lilian Lustosa da Costa ${ }^{3}$
}

\begin{abstract}
Palavras-chave:
Cultura

Infância

Plano

Diversidade cultural

Política cultural
\end{abstract}

Resumo:

\begin{abstract}
A breve análise apresentada neste artigo, trata o exemplo cearense, suas características e problematiza algumas particularidades do campo de políticas culturais num contexto mais recente. O Plano de Cultura Infância elaborado pelo governo do estado do Ceará pode ser um interessante exemplo de valorização de pautas da diversidade cultural e de fortalecimento de posturas da sociedade civil. Os resultados encontrados sinalizam uma peça de planejamento recém aprovada e que possivelmente ainda precisará de redirecionamentos.
\end{abstract}

\footnotetext{
1 Texto recebido em 21/10/2019 e aceito para publicação em 23/10/2019.

2 Deborah Rebello Lima. Doutoranda em Comunicação e Cultura pela Universidade Federal do Rio de Janeiro (UFRJ). Produtora Cultural da Casa da Ciência - Centro Cultural de Ciência e Tecnologia da UFRJ, Brasil. Contato: deborahrebellolima@hotmail.com - https://orcid.org/0000-0002-4598-5347 Responsável pelo Estação Ceará Criativo, escritório de Economia Criativa da Secretaria da Cultura do Estado do Ceará. Contato: lilianlustosa@gmail.com
} 


\section{Resumen:}

El breve análisis presentado en este artículo aborda el ejemplo de Ceará, sus características y problematiza parte del campo de la política cultural en un contexto más reciente. El Plan de Cultura Infantil preparado por el gobierno del estado del Ceará puede ser un ejemplo interesante de valorar las pautas de diversidad cultural y fortalecer las actitudes de la sociedad civil. Los resultados encontrados señalan una pieza de planificación recientemente aprobada y posiblemente aún necesiten redireccionamientos.
Palabras clave:

Cultura

Infancia

Plan

Diversidade cultural

Politica cultural

\section{Keywords:}

Culture

Childhood

Plan

Cultural diversity

Cultural policy

\section{Abstract:}

The brief analysis presented in this article deals with the Ceará example, its characteristics and problematizes some others of the cultural policy field in a more recent context. The Childhood Culture Plan elaborated by the government of the state of Ceará can be an interesting example of valuing cultural diversity guidelines and strengthening civil society attitudes. The results founded highlight a new instrument of planning that may still need redirection. 


\section{Plano de Cultura Infância do Ceará:
um exercício de planejamento \\ umo de Cultura Infância do Ceara:
um excio de planejamento e resultado de escuta de demandas sociais}

\section{Introdução}

Este artigo é parte de um esforço de análise de conjuntura sobre o setor de políticas culturais. Afinal, tendo em vista o decréscimo e a diminuição da centralidade da pauta em nível federal, é fundamental observar os rearranjos que o campo vem percorrendo nos últimos tempos ${ }^{4}$ nos estados e municípios.

Por conta disso, foram dedicados esforços para discorrer sobre as especificidades do Plano de Cultura Infância do Ceará. Ele é uma peça de planejamento importante em si, por dedicar atenção a uma temática que pouco foi desenvolvida, especificamente pelo conjunto das políticas culturais no cenário mais contemporâneo. Da mesma maneira, o exemplo reportado neste trabalho também é pertinente pela forma como foi elaborado e desenvolvido: a partir de demandas e pressão da sociedade civil organizada, mais especificamente do

$4 \quad$ Este artigo é fruto de um trabalho similar desenvolvido, apresentado e publicado no XV ENECULT - Encontro de Estudos Multidisciplinares em Cultura, que ocorreu em agosto de 2019. Naquela oportunidade apresentamos um artigo mais amplo sobre o caso do Ceará e o mesmo está disponível nos Anais do evento (http://www.cult.ufba.br/enecult/ anais/edicao-2019-xv-enecult/). A especificidade desta reflexão dá conta de pensar o modelo do Plano de Políticas Culturais para a Infância e em diálogo com outras ponderações sobre planos nacionais apresentadas neste dossiê.
Grupo Nacional Cultura Infância 5 . Indica, portanto, este movimento contemporâneo em que as ações públicas em cultura não podem mais ser pensadas pelo âmbito exclusivo do Estado. A escuta e a troca sobre as necessidades e pressões de múltiplos grupos da sociedade civil são mais do que pertinentes, fundamentais. Isso reforça o sentido democrático e a importância da participação dos cidadãos na tomada de decisão e na proposição de novas políticas governamentais.

Por outro lado, também toca em uma questão relevante: nos últimos tempos, tivemos um número crescente da elaboração de Planos (peças de planejamento), em diversas esferas da federação, com múltiplas temáticas e intencionalidades. Diante das descontinuidades e das fragilidades institucionais em muitos locais do Brasil, em muitos casos cresce na sociedade civil uma espécie de descrédito em relação à participação. Afinal, é também preciso ponderar sobre a mobilização executada pelo poder público para realizar as metas delineadas e também da sociedade civil para acompanhar o seu desenvolvimento.

\section{O desafio de trabalhar com a diversidade}

É importante pensar a multiplicidade de possibilidades que a noção de diversidade cultural enseja para a construção de políticas públicas. O florescimento dessa pauta

5 O Grupo Nacional de Cultura Infância é um coletivo formado por artistas, pesquisadores, gestores, produtores culturais e projetos socioculturais de diversas partes do Brasil, dentro de um ambiente interativo e construtivo. A pauta que os une é a da militância por políticas culturais de Estado para a infância. Em atividade desde 2014, o Grupo Nacional de Cultura Infância promove um diálogo com a sociedade civil e o poder público, reivindicando programas, ações e recursos públicos para a Cultura Infância nos âmbitos municipal, estadual, distrital e federal. O coletivo realiza o Fórum Nacional Cultura Infância, para sistematizar debates, traçar metas e encaminhar ações. 
no contexto brasileiro, a partir especialmente da primeira década dos anos 2000 , fomentou o surgimento de inúmeras perspectivas de atendimento e de desafios a serem contemplados pelas ações governamentais.

Em âmbito federal, antes mesmo da aprovação da Convenção de Promoção e Proteção da Diversidade Cultural, o Ministério da Cultura, à época, criou uma secretaria reservada a pensar as necessidades provenientes da diversidade cultural: a Secretaria da Identidade e da Diversidade Cultural - SID. De acordo com o decreto ministerial 5.036 de 7 de abril de 2004, que foi responsável pela reforma administrativa do MinC e o redesenho necessário para a elaboração de políticas, a SID teria as seguintes competências:

Art. 11. À Secretaria da Identidade e da Diversidade Cultural compete: I - promover e apoiar as atividades de incentivo à diversidade e ao intercâmbio cultural como meios de promoção da cidadania, a cargo do Ministério; II - acompanhar, em conjunto com a Secretaria de Articulação Institucional da Cultura, a implementação dos fóruns de política cultural, responsáveis pela articulação entre o Ministério e a comunidade cultural; e III - subsidiar a Secretaria de Políticas Culturais no processo de formulação das políticas públicas da área cultural relacionadas com a promoção da diversidade e do intercâmbio cultural e a proteção dos direitos autorais. (BRASIL, 2004, p. 6)

Naquele momento, é possível ponderar que talvez a SID tivesse um papel transversal, uma Secretaria que subsidiaria as demais para a elaboração de políticas. Por isso, era preciso conhecer a diversidade cultural e diversos editais foram lançados com o propósito de mapear as especificidades desse país gigante.

A adoção da diversidade como uma das bases fundantes da política nacional de cultura era visto como elemento essencial, afinal, estava em discussão naquele momento a proposta de uma nova abordagem para o setor. A visão de um Ministério da Cultura voltado exclusivamente para o desenvolvimento de ações vinculadas às linguagens artísticas não dava mais conta da complexidade do mundo contemporâneo, como bem pontuou Gilberto Gil, ministro da Cultura na época:

A multiplicidade cultural brasileira é um fato. Paradoxalmente, a nossa unidade de cultura unidade básica, abrangente e profunda também. Em verdade, podemos mesmo dizer que a diversidade interna é, hoje, um dos nossos traços identitários mais nítidos. É o que faz com que um habitante da favela carioca, vinculado ao samba e à macumba, e um caboclo amazônico, cultivando carimbós e encantados, sintam-se e, de fato, sejam igualmente brasileiros. Como bem disse Agostinho da Silva, o Brasil não é o país do isto ou aquilo, mas o país do isto e aquilo. Somos um povo mestiço que vem criando, ao longo dos séculos, uma cultura essencialmente sincrética. Uma cultura diversificada, plural, mas que é como um verbo conjugado por pessoas diversas, em tempos e modos distintos. Porque, ao mesmo tempo, essa cultura é uma: cultura tropical sincrética tecida ao abrigo e à luz da língua portuguesa. (GIL, 2003, s.p.)

A diversidade passava a ser mais do que uma escolha governamental, era como uma espécie de "reparação da desigualdade", um mecanismo de reconhecimento da importância de todas as manifestações culturais existentes no enorme país chamado Brasil, e não apenas as que historicamente estiveram mais próximas das estruturas de poder e ganharam mais atenção do Estado. Essa abordagem era um elemento na construção da noção de cultura como um direito geral e irrestrito a ser garantido a todos os cidadãos brasileiros. E nesta direção, não apenas o 
direito de acesso às práticas deveria ser fomentado, era preponderante o investimento maciço na garantia de produção de manifestações culturais. O Ministério posicionava-se a "aprender" com a diversidade, a "conhecer" a pluralidade, possibilitando reconhecimento, salvaguarda, proteção e promoção ${ }^{6}$.

Esta visão de diversidade cultural como um exercício de alteridade, como forma de voltar a atuação governamental para as inúmeras práticas de maneira efetiva era um desafio. É possível considerar que a visão do Brasil como uma espécie de caleidoscópio de práticas culturais era quase algo dado, como uma constatação, ou instrumento retórico utilizado em algumas ocasiões. Contudo, a efetiva dimensão dessa diversidade e de suas especificidades era ainda um trabalho bastante complexo a ser desenvolvido.

Nesse contexto, de levante da temática da diversidade cultural, outros desafios foram percebidos, afinal, era fundamental ultrapassar a utilização da diversidade como um instrumento de temática política, como bem pontua José Márcio Barros (2011). Na mesma direção, George Yúdice (2016) sinalizou que é preciso se atentar para o desafio de superar a abordagem inspiracional sobre a diversidade cultural, entendendo-a como o elemento de resolução de inúmeros males sociais. É imprescindível compreender toda a complexidade que se apresenta ao lidar com a diversidade cultural, suas necessidades, seu histórico etc.

Em síntese, a diversidade cultural brasileira não poderia ser tratada apenas como um elemento de aclamação e de celebração da cultura nacional, portanto, conhecê-la apenas não era o suficiente. Percebendo os desafios do tema e o lugar central que este

6 Conceitos-chave na Convenção da Diversidade Cultural aprovada pela UNESCO em 2005. ganhou na gestão, sendo considerado um dos pilares do governo federal, a SID acabou ganhando em importância e tendo suas competências alargadas posteriormente, em 2009 , no decreto $n^{\circ} 6.935$ de 30 de abril de 2009. No entanto, sem perder a função de transversalidade com as outras secretarias.

Art. 16. À Secretaria da Identidade e da Diversidade Cultural compete: I - promover e apoiar as atividades de incentivo à diversidade e ao intercâmbio cultural como meios de promoção da cidadania, a cargo do Ministério; II - instituir programas de fomento às atividades de incentivo à diversidade e ao intercâmbio cultural como meios de promoção da cidadania, a cargo do Ministério; III - planejar, coordenar e executar as atividades relativas à recepção, análise, controle, acompanhamento e avaliação de projetos culturais de incentivo à diversidade $\mathrm{e}$ ao intercâmbio cultural como meios de promoção da cidadania encaminhados ao Ministério; (BRASIL, 2009, p. 7)

Contudo, a pergunta que pode ser feita: onde estava a discussão sobre política cultural para a infância diante de todo o esforço de valorização da diversidade cultural? Para Emídio Sanderson, um dos fundadores do Grupo Nacional Cultura Infância e articulador para o Plano Cultura Infância do Ceará, o debate da diversidade foi potente, mas também revelou tensões no campo, segundo fala deste gestor cultural: "Isso foi ótimo. Mas, por outro lado, criou um ambiente muito bélico, de disputas (envolvendo o recurso público). E o nosso argumento é que, quando a gente fala de infância, é a do indígena, do LGBT, de todos. Foi com essa proposição que entramos nesse território". (DIÁRIO DO NORDESTE, 2017) ${ }^{7}$.

7 Em síntese, a aclamação da diversidade não gerou um ambiente primaveril apenas na sociedade civil, tensões históricas acabaram surgindo no campo. 
No âmbito federal, algumas ações foram realizadas para a construção de políticas que levassem em conta a temática da infância. Em 2008, a SID realizou uma oficina denominada: Brincando com a Diversidade, ainda na mobilização de dados e escuta de demandas da sociedade civil. Já em 2011, a nova Secretaria de Cidadania e Diversidade Cultural (uma junção da SID com a Secretaria de Cidadania Cultural) realizou o I Encontro Nacional de Cultura para a Infância, ocorrido no Rio de Janeiro, também com o intuito de reunir profissionais, pesquisadores e governo, para o debate da pauta e a possibilidade de geração de dados para a construção de políticas. Aos poucos, o grupo de articulação da temática foi se fortalecendo e possibilitou a inserção de uma meta específica no Plano Nacional de Cultura voltada para a infância:

Meta 47 - 100\% dos Planos Setoriais com representação no Conselho Nacional de Política Cultural (CNPC) com diretrizes, ações e metas voltadas para infância e juventude. (BRASIL, 2011, p. 239)

No entanto, não existem dados disponíveis sobre o atingimento dessa meta até os dias de hoje. O que esse trajeto pode sinalizar? Que não se nega a vital importância de valorização da diversidade cultural como centro do entendimento para a cultura, mas é preciso também compreender que a pulverização da demanda torna o percurso de construção de políticas ainda mais lento, mais complexo. É preciso fortalecer questões, disputar espaços e conseguir mobilização suficiente para o atendimento das necessidades.

No caso específico de ações direcionadas para a infância, não podemos falar de completa falta de ações do Estado, contudo, é pertinente sinalizar que esta pauta durante muitos anos foi atendida pelos braços de segurança pública, pela educação e pela assistência social. O olhar específico da área cultural ainda é algo novo e em amadurecimento (com muitas descontinuidades e propostas conflitantes).
Também é pertinente pensar as particularidades desta setorial a partir da cultura, é ainda mais desafiador se o modelo de construção política é focado em instrumentos democráticos. Afinal, quem fala pela infância? De que maneira? Com quais propósitos? O modelo cearense pode pontuar alguns aspectos interessantes nesta discussão.

\section{O Ceará como espaço de resistência}

O trabalho desenvolvido pela Secretaria de Cultura do Estado tem se destacado pela continuidade de algumas políticas estruturantes e grande visibilidade nacional, tais como: o Sistema Nacional de Cultura e a Política Nacional de Cultura Viva. No entanto, não apenas a continuidade da pauta nacional pode ser destacada. Como já retratado em artigo anterior ${ }^{8}$, o caso cearense pode ser visto como um exemplo pertinente de continuidade de uma agenda progressista no que tange ao tratamento da cultura por parte do Estado, ainda que ainda de maneira tímida e um tanto desarticulada.

No caso da temática da infância, é pertinente salientar que parte da articulação feita já na esfera federal, para a criação da meta específica do plano nacional para a temática, teve a participação de grupos cearenses. Após a já mencionada oficina, Brincando com a Diversidade, em 2011, foi organizado o Encontro Nacional de Cultura Infância. Na ocasião, profissionais e instituições que atuam na defesa e promoção dos direitos culturais da criança se reuniram no Rio de Janeiro, debatendo políticas culturais de âmbito nacional para a infância. Há registros de que o grupo de articulação para a criação da meta 47 se estruturou de maneira mais orgânica durante a realização da Mostra de Cinema Infantil de Florianópolis,

8 Disponível em: http://www.cult.ufba.br/enecult/ anais/edicao-2019-xv-enecult 
que nesta edição foi realizado no Ceará, em 2012, que depois de organizado, foi denominado Grupo Nacional de Trabalho Cultura e Infância e apresentaram ao Conselho Nacional de Políticas Culturais um documento com a síntese de suas propostas denominado "Uma Política Pública para a Cultura da Infância" (CENTRO DE REFERÊNCIA NACIONAL CULTURA INFÂNCIA, 2017).

No entanto, vale salientar, que apesar de toda a articulação do grupo, o plano estadual cearense não possui nenhuma meta específica destinada a esta setorial. A inquietação sobre esse dado permitiu uma maior organização da sociedade civil e a pressão aos então candidatos ao governo do estado durante a eleição de 2014.

O Grupo Nacional Cultura Infância, com respaldo da Secult, realizou uma escuta pública com instituições como UNICEF, UFC, UECE e Ministério Público, além dos artistas que trabalham na área, para pautar, juntos aos candidatos à governador a proposta de elaboração de um plano. Quando a nova gestão assumiu a pasta da Cultura, em 2016, o Grupo se reuniu com o secretário para tornar o plano possível.

A proposta da criação de um Plano de Cultura para a Infância do Ceará visava institucionalizar uma política cultural na qual a criança fosse reconhecida como um indivíduo detentor de direitos. O objetivo era então o de levantar, por meio de uma escuta pública, as reais necessidades para a construção de um cenário cultural efetivo, para as crianças cearenses, mobilizando diferentes atores sociais e culturais (QUINTO; CAVALCANTE JÚNIOR, 2017)

\section{O que a análise do Plano em si pode apresentar?}

Em termos de estrutura e definição temática, o plano cumpre o papel de apresentar a setorial, por meio de oito títulos dis- tintos. Em sua estrutura, a legislação delimita as definições do campo, as atribuições do poder público, as especificidades de financiamento, desenha o sistema de avaliação e monitoramento e apresenta as metas específicas. Além, é claro, de especificar sua temporalidade de atendimento decenal.

Sobre a conceituação, delimita a compreensão de infância e, consequentemente de atendimento das ações, de acordo com a faixa etária de 0-12 anos, mas indicando a compreensão da criança como um sujeito de direitos que precisam ser respeitados. Conferindo um caráter autônomo e não tutelado ao escopo do que seria infância. De acordo com o parágrafo único do artigo $1^{\circ}$ da lei de criação do Plano de Cultura Infância do Ceará (Lei nº 122 de 2017):

Parágrafo único. Para os fins desta Lei, entende-se por Cultura Infância o fenômeno social e humano de múltiplos sentidos que abrange, diretamente ou indiretamente, a categoria geracional de 0 (zero) até 12 (doze) anos de idade, perpassando por toda sua extensão antropológica, sociológica, política, ética, estética, simbólica, produtiva e econômica e respeitando as peculiaridades das diferentes fases da infância, sendo a criança, dentro desse escopo, entendida como sujeito histórico-cultural e de direitos com prioridade absoluta, produtor de cultura e capaz de desenvolver suas diversas linguagens, destacando-se o brincar como a sua principal linguagem, a partir daí construindo suas compreensões e significações do mundo e de si própria mediante a interação com outras crianças e com os outros membros da sociedade, sem deixar de considerar a relevância das manifestações artísticas e culturais produzidas e fruídas pela criança, com a criança e para a criança. (CEARÁ, 2017, p.1)

Essa visão humanista e não tutelada sobre a infância é novamente percebida no conjunto de princípios apresentados 
na legislação, com o intuito de observar as particularidades identitárias e de fases da infância, além do Estado laico, da descentralização etc. Esse capítulo também estabelece o sistema de cooperação entre estado e municípios que queiram se unir para a implementação do mesmo. Algo similar do realizado na elaboração do plano nacional, em função do respeito ao nosso sistema federativo e da autonomia dos entes.

O título seguinte especifica, com mais detalhes, as atribuições do poder público na realização das políticas para a infância que vão desde o papel articulador e formador, até indutor para que outros agentes da sociedade civil construam políticas direcionadas para esse público. No que tange às atribuições orçamentárias, o plano é tímido e apenas vincula à setorial a possibilidade de disponibilização de recursos, o que dá um tom discricionário à elaboração das políticas para o setor. Em síntese, não há nenhuma obrigação legal, ou mesmo um fundo específico destinado para as ações. Como sinalizam os artigos 7 e 8 :

Art. $7^{\circ}$ Os planos plurianuais, as leis de diretrizes orçamentárias e as leis orçamentárias do Estado do Ceará, havendo disponibilidade financeira, destinarão recursos a serem empregados na execução de programas, ações e projetos que contemplem a Cultura Infância em todas as suas linguagens artísticas e garantam a execução das ações e estratégias estabelecidas nesta Lei.

Art. $8^{\circ}$ A Secretaria da Cultura do Ceará, na condição de coordenadora executiva do Plano de Cultura Infância do Ceará, deve estimular a diversificação dos mecanismos de financiamento para a Cultura Infância de forma a contemplar as ações e estratégias deste Plano, prevendo, havendo disponibilidade financeira, pelo menos um edital de seleção pú- blica de projetos por ano voltado para a Cultura Infância, com um reajuste de, no mínimo, 5\% (cinco por cento) a cada ano. (CEARÁ, 2017, p. 3)

Da mesma forma, o principal instrumento de financiamento citado pelo Plano é o edital, uma forma de seleção republicana dos projetos a serem financiados, mas um tanto desgastada pelas suas limitações. Chama a atenção também a sinalização da necessidade de buscar mais recursos nacional e internacionalmente, o que indica as dificuldades orçamentárias da pasta da cultura e que não necessariamente foram enfrentadas neste instrumento.

É pertinente indicar que, ainda que o Plano seja um reconhecimento temático importante, sem vinculação orçamentária explícita há uma enorme dificuldade de garantir a execução do planejamento delineado. Tanto que até o momento, apenas uma edição do edital Cultura Infância foi realizada, em 2016, portanto, anterior ao reconhecimento do Plano como Lei. Este edital é um exemplo interessante, porque sinaliza que essa temática gravitava a agenda política cearense não somente pela área da cultura e que a expressiva participação da sociedade civil já existia antes da aprovação do Plano.

O edital Cultura Infância, mencionado anteriormente, teve 25 projetos selecionados, nas categorias Criação, Produção, Circulação e Difusão; Pesquisa e Formação; e Memória Cultural, com um total de orçamento no valor de $\mathrm{R} \$ 986.000,00$. Foram selecionados 13 projetos para o interior e 12 para Fortaleza. As propostas selecionadas eram voltados para formação com oficinas em arte cênicas, música, mamulengos e filmes; produção de livros, revista em quadrinho e cordéis; apresentação e montagem de espetáculos; programação de centros culturais; e um específico para a implantação de um parque interativo. Um tema comum em muitos projetos foi a questão do 
patrimônio, ações voltadas para a preservação da oralidade na cultura indígena, educação patrimonial, tradições, entre outros. Uma nova edição está prevista para 2020.

No que tange à construção da pauta, vale ressaltar que o governo do Estado tem um programa entre secretarias denominado Mais Infância Ceará ${ }^{9}$, que a partir de fevereiro de 2019 teve o projeto de lei aprovado na Assembleia Legislativa tornando-se uma política pública estadual. Com a aprovação do parlamento estadual, o Programa passou a um novo patamar de atuação com garantias de continuidade, já que sua regulamentação resguarda as conquistas já realizadas. E pode ser uma das ações a serem vinculadas às demandas do Plano. O Mais Infância Ceará também é fruto de um amplo diálogo com a sociedade.

No que tange a área da cultura e diretamente ao Plano, o Mais Infância Ceará já entregou aos cearenses 74 brinquedopraças, espaço de lazer para as crianças, e mantém garantida mais 66 equipamentos que estão em execução e análise, além da entrega de cinco Praças Mais Infância e 27 em execução e em licitação. Através de parceria com o Serviço Social do Comércio (SESC-CE), foram atendidas 125 mil crianças e 21 mil pais visitantes e participantes no Espaço Mais Infância, local composto de brinquedoteca, biblioteca infantil, sala de multimídia, cozinha gourmet e cineminha. Além da realização de 131 edições do Arte na Praça, atividades de cultura e lazer para as crianças e suas famílias em praças de 88 municípios.

\footnotetext{
9 Criado em agosto de 2015, a iniciativa defende a necessidade de se ter um olhar especial e mais dedicado à infância, a partir de um diagnóstico da situação do Estado na área e do mapeamento das ações voltadas para o segmento nas diferentes secretarias estaduais. O programa, que abrange os 184 municípios cearenses, busca contemplar a complexidade de promover o desenvolvimento infantil, estruturando-se em quatro pilares: Tempo de Crescer, Tempo de Brincar, Tempo de Aprender e Tempo de Nascer.
}

O Edital Cultura Infância também foi chancelado pelo programa, uma iniciativa pioneira no país com o objetivo de garantir o direito da criança à cultura, à arte para sua fruição, formação e ampliação dos seus repertórios artísticos e culturais. Outro edital também realizado a partir da parceria entre a Secretaria da Cultura e o Mais Infância Ceará foi o Toda Banda de Música é uma Escola ${ }^{10}$, que teve por objetivo apoiar, promover e fortalecer o Sistema Estadual de Bandas de Música do Ceará a partir da seleção dos municípios cearenses para implantação, ampliação ou modernização de suas bandas de música no âmbito do Programa Toda Banda de Música é uma Escola, por meio da cessão de uso de instrumentos musicais e capacitação de crianças e jovens músicos.

O diferencial do edital é que a banda de música é compreendida no referido programa como uma escola livre para educação musical, a qual envolverá músicos profissionais, regentes, arte educadores e escolas da cidade por meio de oficinas, ensaios e apresentações artísticas e demais atividades formativas e de fruição cultural. No edital foram selecionados 20 (vinte) municípios para a categoria Implantação da Banda de Música e 40 (quarenta) na Modernização da Banda de Música. Cada município receberá um kit composto por 46 (quarenta e seis) itens, entre instrumentos e estantes de partitura. O edital teve um orçamento no total de $\mathrm{R} \$ 5.447 .340,00$ voltado para aquisição dos instrumentos.

No que tange ao monitoramento das metas do Plano e da reavaliação das mesmas, a lei determina que seja um trabalho compartilhado entre a Secult, o Conselho Estadual da Criança e do Adolescente do Ceará e o Fórum de Cultura para a Infân-

10 Ação realizada em 2018 e inserida nos debates e proposições demandadas pela sociedade civil. 
cia. Assim como a temporalidade definida para a reavaliação das propostas é de cinco anos. Segundo o artigo 13:

Art. 13. A fim de atualizar e aperfeiçoar o presente Plano, as ações e metas estabelecidas podem ser reestruturadas a cada 5 (cinco) anos, fundamentadas em avaliações quantitativas e qualitativas.

Parágrafo único. A reestruturação a que se refere este artigo deve passar por um processo de consulta pública e pela aprovação do Conselho Estadual de Política Cultural (CEPC), do Conselho Estadual da Criança e do Adolescente do Ceará (CEDCA) e do Fórum de Cultura Infância do Ceará. (CEARÁ, 2017, p. 3)

Os títulos seguintes (da cidadania e diversidade cultural, patrimônio cultural, educação e cultura e linguagens artísticas) versam sobre a interface da temática com outras questões caras às políticas culturais. Nessas seções também é possível analisar as metas específicas de atendimento do planejamento. No geral, o instrumento apresenta, além de definições e proposições conceituais para o setor, oito metas de acordo com a divisão temática já citada.

De fato, o plano não é extremamente longo ou efusivamente detalhado, como alguns observam o Plano Nacional de Cultura, por exemplo. As metas definidas apresentam bons contornos de área, ainda que algumas sejam mais quantificáveis do que outras, o que pode dificultar a mensuração futura de resultados. Propomos uma espécie de classificação quanto à tipologia de cada uma e o seu diálogo com outras áreas da administração pública.

Meta 1: versa sobre o direito de espaços públicos voltados para as crianças para o brincar e o incentivo e acesso à leitura; Meta 2: propõe uma derivação da Política Nacional de Cultura Viva com pontos de cultura voltados para a infância'11; Meta 3: trata de mobilidade, acesso e ações transversais com outras áreas do planejamento público visando a fruição cultural; Metas 4 e 5: enfatizam ações que valorizem o direito à memória e à história das próprias práticas culturais através da participação dos Mestres da Cultura;

Metas 6 e 7: versam sobre a retroalimentação da própria política, a primeira indica a necessidade de mapear as práticas culturais locais para o melhor atendimento ${ }^{12}$, a segunda aponta a necessidade de formação de agentes públicos e da sociedade civil (fazendo a interação com o campo educacional); Meta 8: sinaliza a necessidade de apoio e fomento para instituições que já oferecem ações para esse público.

Após dois anos de publicação do Plano, ainda não existem expressivos resultados quanto ao cumprimento de suas metas. A cultura infância continua em grande parte dos programas e ações da Secretaria da Cultura, mas não com foco programático específico desta. Como enfatizamos anteriormente, só tivemos uma edição do Edital Cultura Infância e anterior a publicação do Plano. Não há um setor que pense e formule políticas para esse público de maneira específica, no cotidiano da gestão, a temática, ainda que prioritária discursivamente, é tratada de maneira transversal e atendida subsidiariamente pelos programas de outras áreas da Secult. A cultura infância teve força de agendamento da sociedade civil e na construção do Plano, contudo, a falta de uma estrutura administrativa específica e de recursos orçamentários consistentes podem dificultar a execução das propostas delineadas.

\footnotetext{
11 Vale ressaltar que o Cultura Viva já executou também ações nessa direção, como os Pontinhos de leitura, por exemplo.
}

12 Uma meta curiosa, não seria uma ação anterior? 


\section{Conclusões}

O exemplo cearense de construção do Plano de Cultura Infância e da realização do Edital Cultura Infância é interessante por alguns motivos: pelo fortalecimento de um elo da diversidade cultural brasileira; pela valorização de uma temática transversal e que tendia a ficar "invisibilizada"; por ser um exemplo de pressão e articulação da sociedade civil e não necessariamente uma iniciativa de "participação tutelada" pelo setor público; e por ser um tema que está em disputa com a agenda conservadora que cresce no país.

Fortalecer a diversidade é tentar estabelecer ações práticas e que dêem corpo e materialidade às figuras discursivas apresentadas à exaustão na primeira década dos anos 2000. Em síntese, retomando Yúdice, estamos trabalhando para superarmos a abordagem inspiracional do tema. Da mesma forma, observar a infância para além de uma noção de segmentação de público, percebendo os desafios de aproximação não é algo simples e não pode ser tratado apenas como uma "fatia" de atendimento. Outro ponto relevante é observar esse percurso de diálogo entre Estado e grupos da sociedade civil, não necessariamente ocorre de forma homogênea e/ou linear.

A abordagem de um tema "invisibilizado" no setor das políticas culturais também é interessante. Por isso o exemplo é potente, por ser uma abordagem na área cultural de um tema que historicamente foi tratado ou pela assistência social ou pela segurança pública.

O exemplo também ilustra o percurso de amadurecimento da sociedade civil, em pleitear posições mais efetivas e do poder público em ouví-la, porém, há que se refletir também sobre a forma de participação em setoriais em que o protagonista (o infanto) não necessariamente tem lugar de fala e poder decisório. Até o momento, quem fala pela infância no exemplo retratado foram grupos da sociedade civil e organizações de escopo internacional, como a UNICEF.

Contudo, o outro lado de construção de um plano como esse é em relação à expectativa gerada nesses mesmos grupos da sociedade civil. Afinal, apresenta-se mais um plano setorial com propostas de atendimento, algumas delas não tão mensuráveis e quantificáveis, o que pode trazer dificuldade de avaliação na efetividade do instrumento de planejamento. José Marcio Barros e José de Oliveira Júnior (2019) ressaltam a dimensão que o plano pode alcançar, como espécie de contrato entre agentes com capacidade decisória distinta, por se tratar de um instrumento de pactuação política centrada na ausculta da sociedade. Fica o questionamento: a pluralidade de estruturas de planejamento colabora com o poder público ou frustra a sociedade civil pela quantidade de demandas represadas e não atendidas em sua plenitude?

Esse debate sobre o Plano de Cultura Infância do Ceará é transversal a essas estruturas de planejamento, pois a questão passa a ser a superação de visualização do instrumento não como um fim em si mesmo, como se a fonte de articulação fosse para ser reconhecido e atendido no planejamento governamental. É preciso ultrapassar essa barreira e batalhar por mais efetividade e entrega nas pactuações ofertadas nos planos de cultura.

Por último, mas não menos importante, o tema é bastante caro ao espectro conservador brasileiro que vem se fortalecendo nos últimos anos, numa efusiva disputa por imaginários e projeções específicas de "valores". Observar uma prática de construção democrática, que dá voz ao contraditório, mas que se preocupa com valores humanísticos sobre a infância brasileira é algo a ser efusivamente valorizado. 


\section{Referências}

BARBALHO, Alexandre. Relações entre Estado e cultura no Brasil. Ijuí: Unijuí, 1998.

BARROS, José Márcio; COSTA, Katia. Planos municipais de cultura: reflexões e experiências. Belo Horizonte: EDUEMG, 2019.

BARROS, José Márcio; OLIVEIRA JUNIOR, José de. Pensar e agir com a cultura: desafios da gestão. Belo Horizonte: Observatório da Diversidade Cultural, 2011.

BRASIL. Decreto ministerial $n^{\circ} 5.036$ de 7 de abril de 2004. Aprova a Estrutura Regimental e o Quadro Demonstrativo dos Cargos em Comissão e das Funções Gratificadas do Ministério da Cultura, e dá outras providências. Brasília, DF, abril, 2004.

BRASIL. Decreto ministerial $n^{\circ} 6.835$ de 30 de abril de 2009. Aprova a Estrutura Regimental e o Quadro Demonstrativo dos Cargos em Comissão e das Funções Gratificadas do Ministério da Cultura, e dá outras providências. Brasília, DF, abril, 2009.

BRASIL. Portaria ministerial n'123 de 13 de dezembro de 2011. Estabelece as metas do Plano Nacional de Cultura - PNC. Brasília, DF, dez, 2011.

CEARÁ. Lei no 122 de 2017. Institui o Plano de Cultura Infância do Ceará. Fortaleza, CE, 2017.

CENTRO DE REFERÊNCIA NACIONAL CULTURA INFÂNCIA. Uma política para a Cultura da Infância. Brasil, 2017. Disponível em: http://www.culturainfancia.org.br/wp-content/uploads/2017/08/ Uma-Pol\%C3\%ADtica-P\%C3\%BAblica-para-aCultura-da-Inf\%C3\%A2ncia.pdf. Acesso em 30 set. 2019.

DIÁRIO DO NORDESTE. O percurso do Plano. Fortaleza, Ceará, 16 de setembro de 2017. Disponível em: https://diariodonordeste.verdesmares.com. br/editorias/verso/o-percurso-do-plano-1.1821179. Acesso em: 30 set. 2019.

GIL, Gilberto. Discurso do ministro Gilberto Gil na solenidade de transmissão do cargo. Brasília: Ministério da Cultura, 2003. Disponível em: http:// www.cultura.gov.br/site/2003/01/02/discurso-doministro-gilberto-gil-na-solenidade-de-transmissao-do-cargo/. Acesso em 12 out. 2015.

LIMA, Deborah Rebello; COSTA, Lilian Araripe Lustosa da. Políticas Públicas de Cultura e
Movimentos de Resistência: O Caso da SecultCE (2015-2018). Anais XV Enecult. Salvador: UFBA, 2019.

QUINTO, Maria Edneia Gonçalves; CAVALCANTE JÚNIOR, Francisco Silva. Estado e Políticas Culturais Para a Infância: qual é o lugar da criança?. VIII Jornada Internacional de Políticas Públicas. São Luís: UFMA, 2017. Disponível em: http://www.joinpp.ufma.br/jornadas/joinpp2017/pdfs/eixo5/estadoepoliticasculturaisparaainfanciaqualeolugardacrianca.pdf. Acesso em 30 set. 2019.

YÚDICE, George. A conveniência da cultura: usos da cultura na era global. Belo Horizonte: Editora UFMG, 2006.

YÚDICE, George. Os desafios do novo cenário midiático para as políticas públicas. Revista Observatório Itaú Cultural, n. 20, p. 87-112, jan-jun. 2016. 